\begin{tabular}{lcr}
\multicolumn{3}{c}{ ANNALES } \\
UNIVERSITATIS MARIAE CURIE-SKŁODOWSKA & \\
LUBLIN - POLONIA & \\
VOL. LXXIII, 1 & SECTIO AA & 2018 \\
\hline
\end{tabular}

\title{
Does the storage time of food packaging material influence the migration degree of 4-phenylobenzophenone photoinitiator from packaging materials to food?
}

Przemyslaw Nowakowski*, Michal Dybowski and Rafal Typek

Faculty of Chemistry, Maria Curie Sklodowska University,

20-031 Lublin, Pl. Maria Curie Sklodowska 3, Poland

*e-mail: przemyslaw.nowakowski@poczta.umcs.lublin.pl

\begin{abstract}
Nowadays, it is not possible to produce food packaging without the use of polygraphic varnishes. Their main task is to protect packaging from the effects of external factors, as well as to give the effect of clarity with greater exposure of the colors used. However, such varnishes contain in their composition low-molecular-weight photoinitiators that can easily migrate to a protected product. The aim of this work was to determine the migration of 4-PBZ from various types of substrates used in the printing industry, i.e. paper, aluminum foil and polyethylene foil. In addition, extensive studies on the impact of the storage conditions of a fresh reprint on the change in the migration of the photoinitiator to food were carried out.
\end{abstract}

Keywords: photoinitiator migration; 4-phenylbenzophenone; polygraphic varnish; UV curing; polygraphic substrates

\section{INTRODUCTION}

The increasing complexity of materials used in the production of packaging draws researchers attention to the possible consequences 
of the presence of certain substances affecting human health and the environment in which they are found. This issue is of particular importance in the case of food packaging [1,2]. Particular attention is paid to polygraphic varnishes [1], whose task is both to protect the packaging from external factors and to give clarity and depth to the colors used. According to the guidelines of the European Union (GMP-EC Regulation No. 2023/2006 of 22 December 2006 [3] regarding good manufacturing practice for materials and articles intended for contact with food and Commission Directive 2003/94/ EC [4] with regard to good manufacturing practice of medicinal products for use and medicinal products for human use in the test phase) guidelines, materials in contact with food must be manufactured in the way, to prevent substances which may endanger consumers health from entaching food, and consequently contribute to the deterioration of the taste or aroma of the food being protected. This process is expertly defined as "component migration" and its degree should be monitored $[1,2,5]$.

Currently, the most commonly used polygraph coatings are varnishes cured with EB (Electron beam) $[5,6]$ or UV (Ultraviolet) $[7,8]$ radiation. Due to the economics of the process usually the latter is chosen. In trade, free-radical varnishes cured with UV radiation are the most widespread [7,8]. Such varnishes contain in their composition low molecular weight photoinitiators, which under the influence of UV radiation initiate the polymerization process of reactive liquid varnish components creating a hardened coating [9-13].

One of the more common photoinitiators used to cure varnish and the only of benzophenone derivatives not excluded from contact with food is 4-phenylbenzophenone (4-PBZ) [14]. The popularity of 4-PBZ results from its high reactivity, which implies in a high rate of curing of the varnish layers. However, it has some weaknesses. It has allergenic properties, causing irritation of the eyes and skin, it can penetrate into the bloodstream. This compound poses a hazard to the natural environment $[14,15]$. Therefore, it is extremely important to monitor its migration from the varnish layer to food [16-18].

This paper presents the impact of storage of packaging protected with a UV-curing varnish coat on the degree of migration of unreacted photonitiator, which was 4-PBZ. 


\section{EXPERIMENTAL}

\subsection{Materials and chemicals}

The analyte migration process was carried out by its extraction into the D2 model fluid, which constituted 95\% ethanol which imitates fatty foods $[19,20]$.

The following polygraphic substrates were used: paper (Alaska Plus $280 \mathrm{~g} / \mathrm{m} 2$ ), polyethylene foil (PE) (150 $\mu \mathrm{m}$ thickness) and aluminum foil (thickness 450 - $550 \mu \mathrm{m}$ ).

Polygraphic varnish most often used in practice was a mixture of the following ingredients:

- glyceryl [4PO] triacrylate $49.0 \%$

- bisphenol A epoxy acrylate $35.5 \%$

- amine synergist 9.5\%

- dimethylsiloxane $1.5 \%$

- 4-phenylbenzophenone $4.0 \%$

- dimethylsiloxane modified by polyethers $0.5 \%$

Ethanol (chemical purity grade) and aluminum foil (thickness 450-550 $\mu \mathrm{m}$ ) were supplied by Krakchemia (Krakow, Poland). Polyethylene (PE) foil (150 $\mu \mathrm{m}$ thickness) was supplied by TART (Czech Republic) and paper (ALASKA PLUS $280 \mathrm{~g} / \mathrm{m}^{2}$ ) by International Paper (Tennessee, USA). 4-phenylbenzophenone (4-PBZ) (99.9\%), benzophenone (99), glyceryl [4PO] triacrylate (99\%), bisphenol A epoxy acrylate (99\%), amine synergist (i.e. reaction products of diethylamine with [2-propenoic acid and and 1,1'-[(1methyl-1,2-ethanediyl)bis[oxy(methyl-2,1-ethanediyl)]] ester]) (99\%) and dimethylsiloxane (99\%) dimethylsiloxane modified by polyethers (99\%) were purchased from Sigma (Poznan, Poland). Deionized water was purified on a Milli-Q system from Millipore (Millipore, Bedford, MA, USA).

\subsection{Formation of a surface varnish layer}

The sheets of paper, aluminum foil, and PE foil were coated by Flexiproof 100 (RK PrintCoat Instruments Ltd, Litlington, United Kingdom) with varnish composed of glycerol [4PO] triacrylate, bisphenol A epoxy acrylate, amine synergist, dimethylsiloxane, 4-PBZ and dimethylsiloxane modified by polyethers. $6 \mu \mathrm{m}$ varnish 
layers were formed on the applied support materials using rollers containing 160 cells per liner. The layers were cured employing the UV curing system from GEW (GEW (EC) Limited) applying 100 $\mathrm{mJ} / \mathrm{cm}^{2}$ UV dose. The used UV curing system allows for varnish curing in stable temperature. For statistical purposes each varnish layer was prepared three times. Before each curing procedure, the power of the UV lamp was controlled by a UV integrator (Technograph Gmbh, Germany). The coated sheets were cut into squares $(10 \mathrm{~cm} \times 10 \mathrm{~cm})$ and subjected to further experiments.

\subsection{Examination of 4-phenylbenzophenone migration}

Estimation of 4-PBZ migration was performed accurately according to EN 1186-1, EN 1186-14 and PN-EN 13130-1 [21-23]. The pieces of individual packaging materials $(10 \mathrm{~cm} \times 10 \mathrm{~cm})$ with layer of the varnish were extracted by $2 \mathrm{hrs}$ at $60^{\circ} \mathrm{C}$ using $100 \mathrm{~cm}^{3}$ of simulant D2 (95\% ethanol). The extraction process was carried out in the migration cell type E (ISEGA, Gmbh, Germany). The obtained extracts $\left(10 \mathrm{~cm}^{3}\right)$ were spiked with ethanolic solution of benzophenone (internal standard) $\left(20 \mathrm{~mm}^{3} \mathrm{c}=0.25 \mathrm{mg} / \mathrm{cm}^{3}\right)$ and subjected to GC analysis.

\subsection{Chromatographic analysis}

For qualification and quantification of 4-PBZ in the obtained extracts (experiments for the estimation of 4-PBZ migration degree) and for qualification of ethanolic extracts from PE foil, aluminum foil and paper (experiments for the determination of the indicative composition of additives contained in the applied packaging materials), gas chromatograph with mass spectrometer detector GC-MS (GC-MS 2010, Shimadzu, Kyoto, Japan) equipped with ZB-Semi Volatiles capillary column $(30 \mathrm{~m} \times 0.25 \mathrm{~mm}$ i.d., $0.25 \mu \mathrm{m}$ film thickness; Phenomenex, USA) was used. Helium (grade 5.0) with flow rate $1.00 \mathrm{~cm}^{3} / \mathrm{min}$ as carrier gas was used. $1 \mu \mathrm{l}$ samples were injected by an AOC - 6000 autosampler (Shimadzu, Kyoto, Japan). The injector temperature was $300^{\circ} \mathrm{C}$. The following temperature program was applied: $4 \mathrm{~min}$ at $35^{\circ} \mathrm{C}$ and then a linear temperature increase up to $250^{\circ} \mathrm{C}$ at the rate of $5^{\circ} \mathrm{C} / \mathrm{min}$. The mass spectrometer was operated using electron ionization (EI) mode at $70 \mathrm{eV}$; the ion source temperature was $220^{\circ} \mathrm{C}$. The chromatographic analysis was carried 
out in SIM mode monitoring ions characteristic for 4PBZ $(\mathrm{m} / \mathrm{z}=152$, $\underline{181}$ and 258$)$ and benzophenone $(\mathrm{m} / \mathrm{z}=77, \underline{105}$ and 182).

\section{RESULTS AND DISCUSSION}

Fig. 1. shows the degree of migration of 4-PBZ from various types of substrate, i.e. paper, aluminum foil and polyethylene foil. According to the obtained data, the highest level of migration of the analyte is observed when paper is used as the varnish substrate. In this case, the 4-PBZ migration is about 35\% higher than for aluminum substrate and up to $55 \%$ higher than for polyethylene substrates. This result is so surprising that the varnish was applied in the same amount and cured under identical conditions. The differences in the degree of component migration are most likely the result of influence of the substrate type on the degree of cross-linking of the varnish and its adhesion to the substrate on which it was applied.

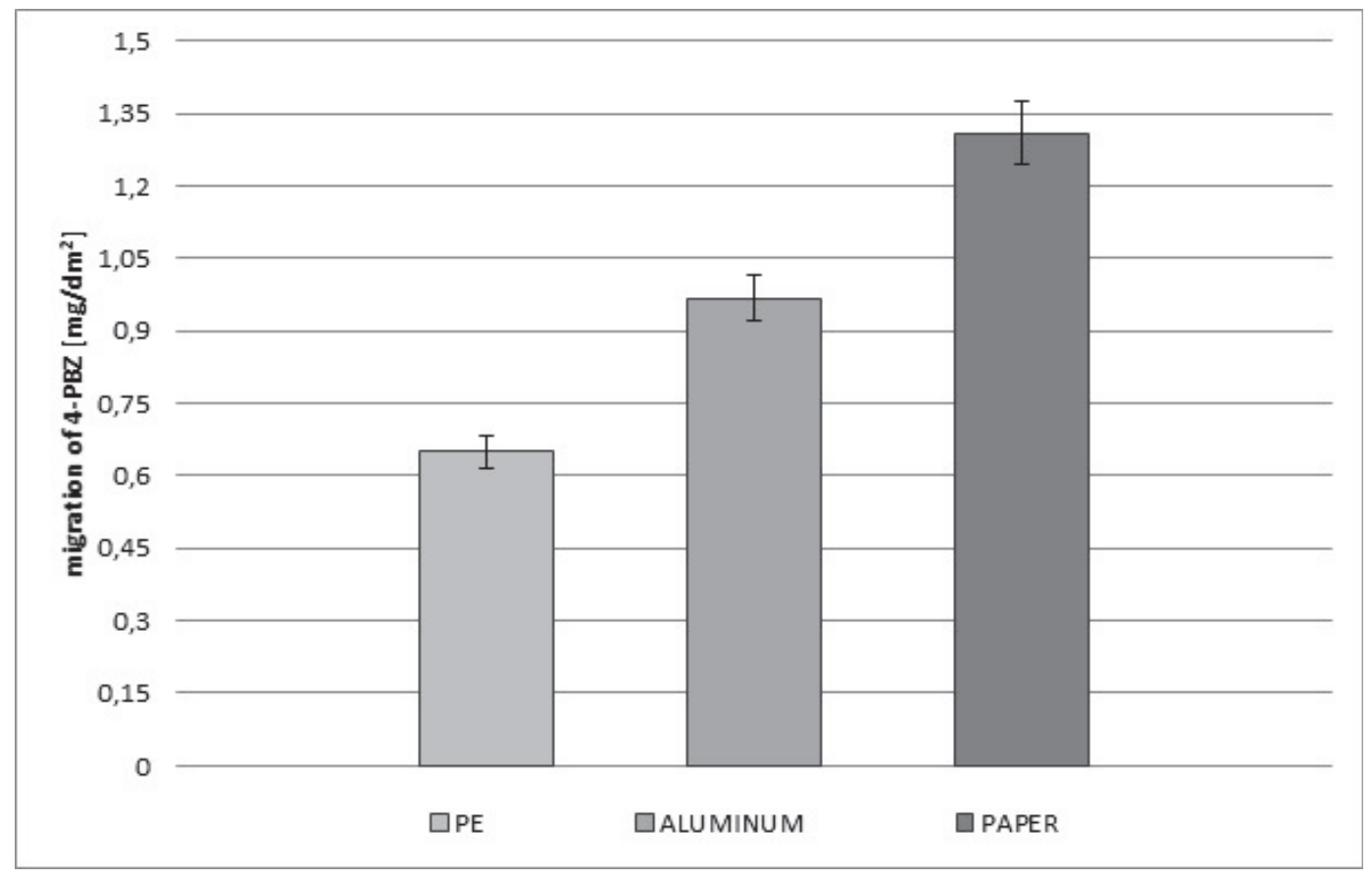

Fig. 1. Migration degree of 4-PBZ from various types of substrates, i.e. paper, aluminum foil and polyethylene foil.

With this in mind, it was decided to conduct an experiment, the purpose of which was to verify whether the conditions of storage of a 
freshly prepared reprint affect the change in the degree of migration of the photoinitiator to food. For this purpose, identical varnish layers of $6 \mu \mathrm{m}$ were applied on substrates. Reprints were left for 24 and 48 hours in a darkened room, and at the same time (i.e. 24 and $48 \mathrm{hrs}$ ) were exposed to UV light. The obtained results of the migration test of the 4-PBZ photoinitiator are shown in Fig. 2. (PAPER light and dark: star and triangle; Aluminum light and dark: circle and square with plus; PE foil light and dark: square and rhombus).

There is lack of data in the literature regarding the impact of packed products storaging on the photoinitiators migration degree. There are only few available articles describing the impact of storaging of alloyed coatings using solvent components on the emission of low-molecular volatile organic compounds [24-27]. Nowadays varnish coatings cured by UV radiation have become very popular. These coatings are cheaper and more environmentally friendly in production $[1,2,28]$. With time, low-molecular photoinitiators included in UV varnish, can migrate to foodstuff $[13,29]$. Therefore, it is important to get to known the possibility of photoinitiators migration into food products during storaging.

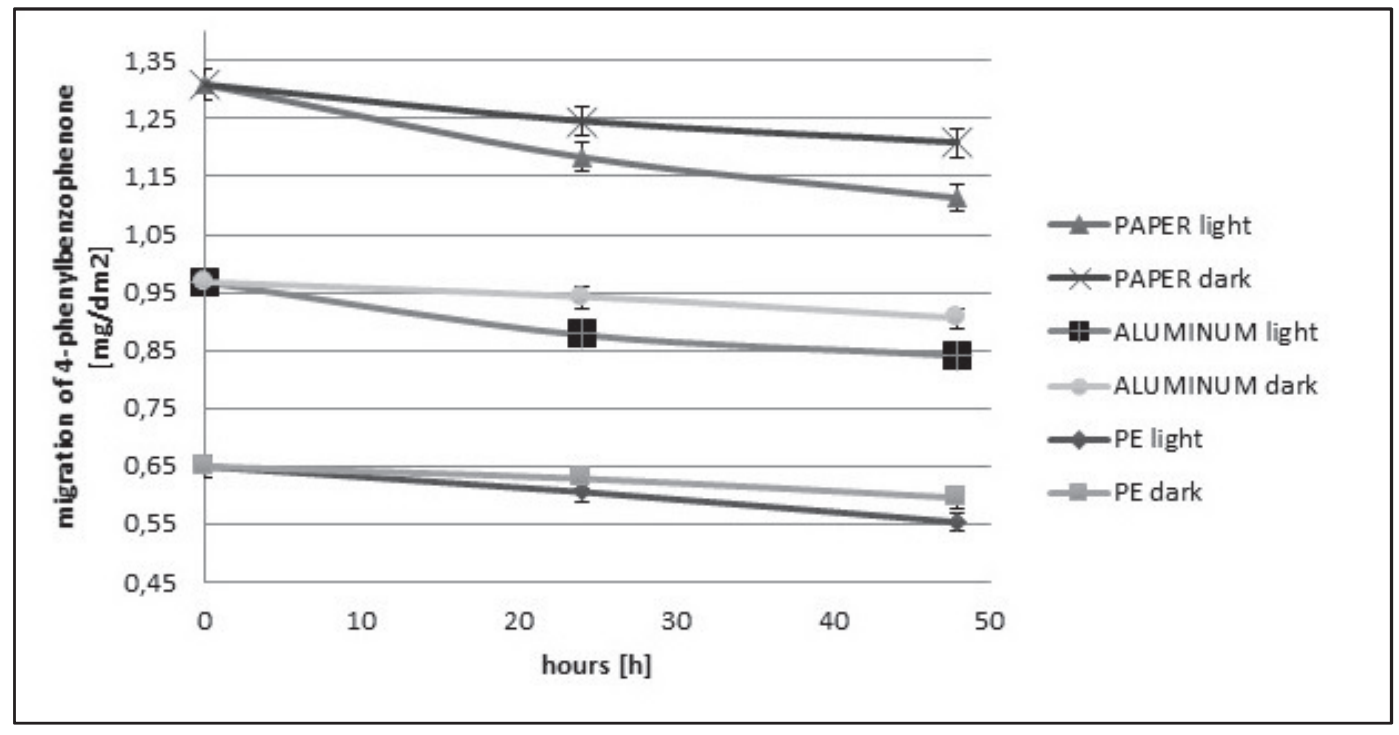

Fig. 2. Migration of a stored reprint from $6 \mu \mathrm{m}$ layer after 24 and 48 hours in a darkened room and exposed to UV light.

As can be seen from the data presented, the migration of 4-PBZ from the varnish coating is observed in the case of reprints stored in a shaded room as well as reprints subjected to UV radiation. This is 
due to further cross-linking of the varnish surface. It is worth noting here even bigger decline is observed in the case of varnish subjected to UV radiation, which to a certain extent would most probably confirm the earlier thesis.

\section{CONCLUSIONS}

At present a lot of attention is paid to polygraphic varnishes, whose task is both to protect the packaging from external factors and to give clarity and depth to the colors used. Due to the excellent aesthetic qualities, UV varnishes have gained enormous popularity. However, it should be noted here that in their composition they often contain harmful photoinitiators that can migrate to the protected product.

This paper attempts to investigate the type of substrate used and the method of storing the varnish layer on the degree of migration of a 4-PBZ photoinitiator into a food product. As it results from the presented research findings, the type of substrate used has a key impact on reducing migration of the photoinitiator from the polygraphic varnish layer. The smallest amount is emitted from the PE substrate, the largest of paper (relative increase in 4-PBZ migration by approx. 55\%). In addition, in the case of reprints stored for 48 hours with additional exposure to UV light, a significant decrease in the emission of the photoinitiator was observed. Therefore, in order to reduce the emission of harmful photoinitiators from food packaging, and thus reduce the risk of negative impact of these substances on human health, it is recommended to use a polyethylene substrate and additionally "lagering" of reprints before using them for food packaging

\section{REFERENCES}

[1] B.B. Mesic, L.O. Sherman, Flexo by name, flexible by nature Printing Functional coatings and graphics, Appita Jurnal., 70, 106-110, (2017).

[2] L. Steuer. Flexo INK forecast, Trade Jurnal., 42, 54-55, (2017). 
[3] Commission Regulation (EC) NO 2023/2006 of December 2006. On good manufacturing practice for materials and articles intended to come into contact with food. Official Jurnal of the European Union; 2006.

[4] Commission Directive 2003/94/EC of 8 October 2003 laying down the principles and guidelines of good manufacturing practice in respect of medicinal; 2003, Products for human use and investigational medicinal products for human use.

[5] H. Steve. Reactive inkjet formulations - Curing by electron beam. International Conference on Digital Printing Technologies, 652-655, 2009.

[6] D. Biro, J. Bishop, Advances in electron beam curing in wide web flexible package printing. Proceedings of the Technical Association of the Graphic Arts, TAGA, 143-147, (2017).

[7] M. Aydin, N. Arsu, Y. Yagci, S. Jockusch, N.J. Turro, Mechanistic study of photoinitiated free radical polymerization using thioxanthone thioacetic acid as one-component type II photoinitiator, Macromolecules, 38, 4133-4138, (2005).

[8] B. Mertens, E. Van Hoeck, M.N. Blaude, C. Simon, M. Onghena, T. Vandermarken, K. Van Langenhove, H. Demaegdt, K. Vandermeiren, A. Covaci, M.L. Scippo, M. Elskens, J. Van Loco, Evaluation of the potential health risks of substances migrating from polycarbonate replacement baby bottles. Food Chem Toxicol, 97,108-119, (2016).

[9] Clemente, M. Aznar, C. Nerin, O. Bosetti, Migration from printing inks in multilayer food packaging materials by GC-MS analysis and pattern recognition with chemometric, Food Additives \& Contaminants: Part A,;33(4), 703-714, (2016).

[10] G. McCombie, M. Biedermann, Migration From Food Contact Materials, Reference Module in Food Science, 2018.

[11] M. Aznar, C. Domeno, C. Nerin, O. Bosetti, Set-off of non volatile compounds from printing inks in food packaging materials and the role of lacquers to avoid migration, Dyes and Pigments. 114, 85-92, (2015).

[12] A.S. Silva, R.S. Garcia, I. Cooper, R. Franz, P.P. Losada, Compilation of analytical methods and guidelines for the determination of selected model migrants from plastic packaging, Trends Food Sci Technol., 17, 535-46, (2006).

[13] A.S. Silva, R.S. Garcia, Photoinitiators in Printed Food Packaging: Migration and Food Safety Concerns, Reference Module in Food Science, 2017.

[14] Nestlé Guidance Note on Packaging Inks, August 2016. 
[15] European Chemicals Agency ECHA 4-phenylbenzophenone, available at: https://echa.europa.eu/pl/substance-information/-/substanceinfo/ 100.016.678. Accessed 2018.

[16] Y. Zhang, Z. Du, Z. Xia, Q. Guo, H. Wu, W. Yu, Evaluation of the migration of UV-ink photoinitiators from polyethylene food packaging by supercritical fluid chromatography combined with photdiode array detector and tandem mass spectrometry, Polymer Testing, 53, 276-282, (2016).

[17] D. Chung, S.E. Papadakis, K.L. Yam, Simple models for assessing migration from food-packaging films, Food Addit Contam, 19, 611617, (2002).

[18] N. Jakubowska, G. Beldi, A.P. Bach, C. Simoneau, Optimization of an analytical method and results from the inter-laboratory comparison of the migration of regulated substances from food packaging into the new mandatory European Union simulant for dry foodstuffs, Food Addit Contamin, 31, 546-555, (2014).

[19] Regulation (EC) No 1935/2004 of the European Parliament and of the council of 27 October 2004 on materials and articles intended to come into contact with food and repealing Directives 80/590/EEC and 89/109/EEC; 2004.

[20] Commission Regulation (EU) No 10/2011 of 14 January 2011 on plastic materials and articles intended to come into contact with food; 2011.

[21] The European Standard PN-EN 1186-1. Materials and articles in contact with foodstuffs - Plastics - Part 1: Guide to the selection of conditions and test methods for overall migration. This European Standard was approved by CEN; 2002.

[22] The European Standard PN-EN 1186-14. Materials and articles in contact with foodstuffs - Plastics - Part 14: Test methods for 'substitute tests' for overall migration from plastics intended to come into contact with fatty foodstuffs using test media iso-octane and 95 \% ethanol. This European Standard was approved by CEN; 2002.

[23] The European Standard PN-EN 13130-1. Materials and articles in contact with foodstuffs - Plastics substances subject to limitation Part 1: Guide to test methods for the specific migration of substances from plastics to foods and food simulants and the determination of substances in plastics and the selection of conditions of exposure to food simulants. This European Standard was approved by CEN, 2004.

[24] J. Muncke, Migration, Food Packaging \& Health, 2013

[25] Arvanitoyannis, L.A. Bosnea, Migration of Substances from Food Packaging Materials to Foods, Critical Reviews in Food Science and Nutrition, 44, 63-76, (2004). 
[26] A. İçöz, B. Eker. Selection of food packaging material, migration and its effects on food quality. $1^{\text {st }}$ International conference on Quality of Life June 2016.

[27] J.M. Krochta, Food packaging, in: Handbook of Food Engineering, 2nd edn, (D.R. Heldman, D.B. \& Lund, Eds), Boca Raton, Florida, 847-927, (2007).

[28] S.S. Sablani, M.S. Rahman, Food packaging interaction,in: Handbook of food preservation (M.S. Rahmna, Ed.), Boca Raton, F.L., CRC Press, Taylor and Francis, 39-56, (2007).

[29] N. Rastkari, M.Z Jeddi, M. Yunesian, R. Ahmadkhaniha, The effect of storage time, temperature and type of packaging on the release of phthalate esters into packed. Food Technology \& Biotechnology. 55, 562-569, (2017). 